\title{
Inequality of digital access between Russian regions
}

\author{
Olga Buchinskaia ${ }^{1 *}$, and Elena Stremousova ${ }^{2}$ \\ ${ }^{1}$ Institute of Economics, Ural Branch of RAS, Territorial Competition Sector, Ekaterinburg, 620014, \\ Russia \\ ${ }^{2}$ Ural State University of Economics, World Economy and Foreign Economic Activity Department, \\ Ekaterinburg, 620144, Russia
}

\begin{abstract}
With the development of digital technologies, an increasing number of economic relations are carried out via the Internet. The absence of Internet access may increase inequality within the regions and between them. This study aimed to measure the divide in the use of Internet technologies by organizations and households. This divide is the basis of digital inequality in the regions of the Russian Federation. As a method to achieve this goal, the authors propose using the index of rating assessment of digital access. This index was calculated for the private sector and households only to illustrate the arrearage of households in access to the Internet. During the analysis, the authors identified regions with high potential for the development of digitalization, as well as lagging regions, and analyzed sources of this lagging for the regions with low access to the Internet. The results of this study can be used as a method for the express analysis of the Internet development in the regions, determining the degree of interregional inequality in accessing digital services and improving the National Program of Digital Economy for Russia.
\end{abstract}

Keywords: digital inequality, Internet, regional differentiation.

\section{Introduction}

The development of digital technologies increasingly affects economic and social life and significantly changes the structure of interaction between economic entities. The very presence of digital technologies, their availability, skills of working with digital equipment and digital data are significant factors in ensuring the competitiveness of the regions. Inequality in the access to and use of digital technologies leads to an increase in other types of inequality. Van Dijk [1] allocates 10 aspects of inequality that the inequality in access to digital technologies can cause: inequality in the level of education, social inequality, material and intangible inequality, and inequality in the technological possibilities of working activities. Thus, digital inequality can lead to a significant economic divide between the countries and regions. As a result of Matthew's effect, this gap increases [2]. In this regard, there is a serious problem of studying the digital inequality of the regions of

\footnotetext{
* Corresponding author: gto2000@list.ru
} 
Russia, which can lead to the lagging for specific regions, a decrease in the general production capabilities and quality of life in certain regions of the Russian Federation, and the deepening of economic inequality in the country. However, before evaluating the success of digitalization processes, it is necessary to assess the preparedness of the regions for the introduction of digital services. It is connected with the equipment of the population and organizations with digital devices and Internet access.

This study aims to detect the divide in the access to and the use of the Internet, which causes digital inequality in the regions of the Russian Federation. The identification of the digital inequality level allows pinpointing the regions lagging behind in access to digitalization for a more detailed factor analysis of causes of insufficient Internet usage and its elimination.

\section{Literature review}

The problem of digital inequality arose relatively recently due to the youth of digital technologies themselves. The first publications on this topic appeared in the late 1990s and the beginning of the 2000s and were dedicated to the concept of the digital divide, which was originally seen as a difference in access to the Internet, or use or non-use of digital technologies [3]. At the micro-level, that access was associated with racial, gender issues, and welfare problems [4]. Nanthikesan [5], exploring the digital divide at the macro level, described the following limitations that form a digital gap: connectivity (the possibility of physical internet access), financial accessibility, local content and language availability, the ability to apply digital technology, both at the individual and collective level, and the opportunities to invest in digital infrastructure.

The term "digital inequality" appeared almost simultaneously with the term "digital divide". Digital inequality displays the further unequal development of the digitalization processes: the formal access to the Internet is present, but there are differences in the convenience and efficiency of the Internet usage. For example, Dimaggio and Hargittai [6] define 5 parameters for the development of digital inequality, including the difference in the equipment and methods for connecting to the Internet, the difference in the availability and autonomy of the connection, the difference in the skills of using digital technology and the Internet, the difference in the availability of public support from the Internet communities, and distinction for the use of the Internet. However, the digital divide predetermines digital inequality.

While analyzing the digital discharge at the level of federal districts, Gladkova and Ragnedda [7] allocate three levels of the digital divide: access inequality, digital literacy, and the level of digitalization in regions.

The authors note that digital literacy does not always correlate with the presence of Internet access, so in the Far Eastern Federal district, with a relatively low level of access, there is a high level of digital literacy.

Grischchenko [8] notes a decrease in the digital divide in Russia, primarily because of the alignment of the age of Internet users, as most Internet users now are in the middle-age group, while the relevant gap remains for groups of the population up to 25 and from 65 years old. Inequality in income now causes the most significant component of the digital divide.

Some researchers agree that digital inequality is linked with the quality of life level, and thus it has a significant impact on the level of socio-economic development of the regions. For example, Litvinseva and Karelin [9] propose to consider the level of quality of life of the population, accessing the level of digitalization, with the help of the Russian regional index of the digital component of the quality of life of the population (RRIDCQLP). As the illustration of the digital inequality impact, they introduce the results of the calculation of 
the effect of RRIDCQLP on the GDP per capita. Polojikhina [10], assessing the dynamics of the index of readiness to the information society of some Russian regions, shows a rather strong gap between the regions. Moscow and St. Petersburg, as well as the Khanty-Mansi and Yamalo-Nenets Autonomous Areas, were leaders of the rating, while the KarachayCherkess Republic, Ingushetia, and Dagestan turned out to be the least ready. Regarding the interpersonal digital inequality, which takes place in all regions, both Polojikhina [10] and Schinkaeva and Slepova [11] noted that the age of 56 and higher, the level of education and digital literacy, as well as the income level, affected the digital inequality. Lyaskovskaia [12], based on index of the digital inclusion of the subject of the Federation, also shows the leading role of Moscow and St. Petersburg and the lagging position of the Republics of the Caucasus, but the third and the fourth places in his rating are occupied by the Novosibirsk and Kaluga Regions, while the Khanty-Mansi and Yamalo-Nenets Autonomous Areas occupy the 30th and 39th places of the rating.

So, the different calculation systems are not yet able to give a fully accurate picture of digital inequality. However, all of them show the leading role of Moscow and St. Petersburg and the essential lag of other regions. Sharifyanov [13] explains this phenomenon with a deficit of the infrastructure between the center and remote areas, as well as with the weakening and dispersal demand for digital products given the urbanization and population reduction in remote areas, primarily loss of young inhabitants. Groshov and Krasnoslobodsev [14] note a significant correlation between the digitalization index and the creativity index, which is not only determined by the specifics of the production specialization of regions (the service sector for "creative regions" and material production for "not creative" ones). This effect also prevents the development of "creative" activity in regions with "digital poverty". Thus, the problem of finding the origins and degree of digital inequality among Russian regions is currently important. Its solution will allow achieving more equal development of territories both in a digital and socio-economic aspect.

\section{Methods}

The authors propose an integral assessment of the rating of digital access in Russian regions using the data from the official Russian statistic portal of Rosstat. For the study, the data of 2018 were used to access the level of Internet penetration in regions. The authors used static data as, according to Sicherl [15], the growth rates of digital indicators are uneven: they are higher for developing regions and are sufficiently low for regions with a high level of digitalization.

The assessment methods imply three stages. In the first stage, the authors collected a sample of indicators. In the second stage, the selected data were normalized using the minimum formula and ranked from 0 to 100 , where 0 displays the minimum level of use of the indicator and 100 - the maximum level of use of the indicator:

$$
\hat{x}=\frac{X-X_{\min }}{X_{\max }-X_{\min }} \times 100,
$$

where $\hat{x}$ is the normalized value of the indicator; $\mathrm{X}$ is the value of the indicator in the region; $\mathrm{X}_{\min }$ is the minimum observed value of the indicator; $\mathrm{X}_{\max }$ is the maximum observable value of the indicator.

In the third stage, a rating assessment of digital access (RADA) is carried out by the average arithmetic amount of varying values of the rating assessment of values of indicators characterizing the development of digitalization in the regions: 


$$
R A D A=\sum_{i, j=1}^{n}=\frac{X_{i j}}{n},
$$

where $\mathrm{X}_{\mathrm{ij}}$ is the rating location of the $i$-th indicator of the $j$-th region; $\mathrm{n}$ is the number of estimated indicators.

As indicators for this study, the authors used:

- the use of information and communication technologies (ICT) in organizations,

- the use of the Internet in organizations.

These two indicators describe the ability of organizations to use digital services and the possibility of connecting existing equipment to the Internet. To define the availability of digitalization for households, the authors used:

- the percentage of households with Internet access,

- the number of subscribers with a fixed broadband connection per 100 individuals,

- the number of subscribers with mobile broadband connection per 100 individuals,

- the amount of data transmission via the Internet, Petabyte (PB) per 1000 individuals.

According to the results of the assessment, there is a comparison of the rating of the digital inequality, considering the indicators of only households and the combined assessment of households and organizations. This allows evaluating the general digital inequality between the regions and the digital divide for households, which is more significant for the digitalization of the Russian economy since most of the enterprises already have the Internet connection. The difference between these indicators allows estimating the lag of the household digitalization level.

When analyzing the results, the authors excluded from the analysis Moscow and St. Petersburg, as a priori leading regions, and the Moscow and Leningrad Regions, since several indicators for these areas are calculated including the capital cities, which gives significant distortion in the ranking for these regions.

\section{Results}

In general, the analysis of indicators shows the quite uneven use of Internet technologies between economic subjects: the digitalization of enterprises is usually 1.02-1.49 times higher than the digitalization of households. The highest gap is shown by the Chuvash Republic, the Transbaikal Territory, and the Yaroslavl Region. The regions where access to the Internet at households turned out to be higher are the Republic of Tuva, the Republic of Buryatia, and the Chukotka Autonomous Area. In almost all regions, the broadband mobile Internet connections are 2 or more times higher than fixed broadband access.

In the Republic of Ingushetia, the quantity of broadband mobile Internet users was 43.75 times higher than that of clients of fixed broadband. In the Republic of Dagestan, this indicator was 22.92, in the Chechen Republic - 15.16, and in the Republic of Tuva - 10.14. The only region where the number of users of the fixed Internet exceeds that of users of the mobil Internet is the Sevastopol City, with a ratio of 0.44 . The authors observed the approximately equal use of the mobile and fixed Internet in the Republic of Crimea (1.05). Thus, a lack of fixed Internet development is visible, although it has such advantages as non-fixed traffic, greater stability and speed of information transfer so providing better access for office and remote workplaces, cloud computing, the use of digital television and other services requiring large traffic. Thus, inequality in the amount and quality of connections sets the basis for a significant digital inequality between the regions.

After the calculations were carried out, all analyzed regions were ranked in descending order of the RADA on a comprehensive assessment of organizations and households. For comparative analysis of the level of digital inequality, the authors divided the RADA values into 3 groups: 
- the high availability of digitalization with RADA rating from 60 to 100 (Figure 1);

- the mid-level availability of digitalization, RADA from 50 to 59 (Figure 2);

- the low availability of digitalization, RADA from 0 to 49 (Figure 3 ).

In the group with the high availability of digitalization (32 regions, not taking into account Moscow and St. Petersburg), the Magadan Region, Republic of Tatarstan and Kamchatka Territory occupy the leading places in the rating. This is because by several indicators, these regions had a high meaning compared to others: the Magadan Region ranked first in the RADA, demonstrated second place in the share of households with the Internet $(87.7 \%)$, third place in the amount of traffic per 1000 people $(0.412 \mathrm{~PB})$, fifth place in the number of mobile broadband Internet users (105) per 100 people. The second place of Tatarstan in the availability of digitalization is because of high positions in all components of the rating, which demonstrates the harmonic digital development of the republic. It does not contradict other rating estimates. The Kamchatka Territory, which took third place in the RADA ranking, also shows the high number of users of broadband mobile Internet (102.5), and its volume of traffic $(0.46 \mathrm{~PB})$ is even higher than that of Magadan. At the same time, Kamchatka is significantly inferior in the share of households with the Internet $(77.5 \%)$.

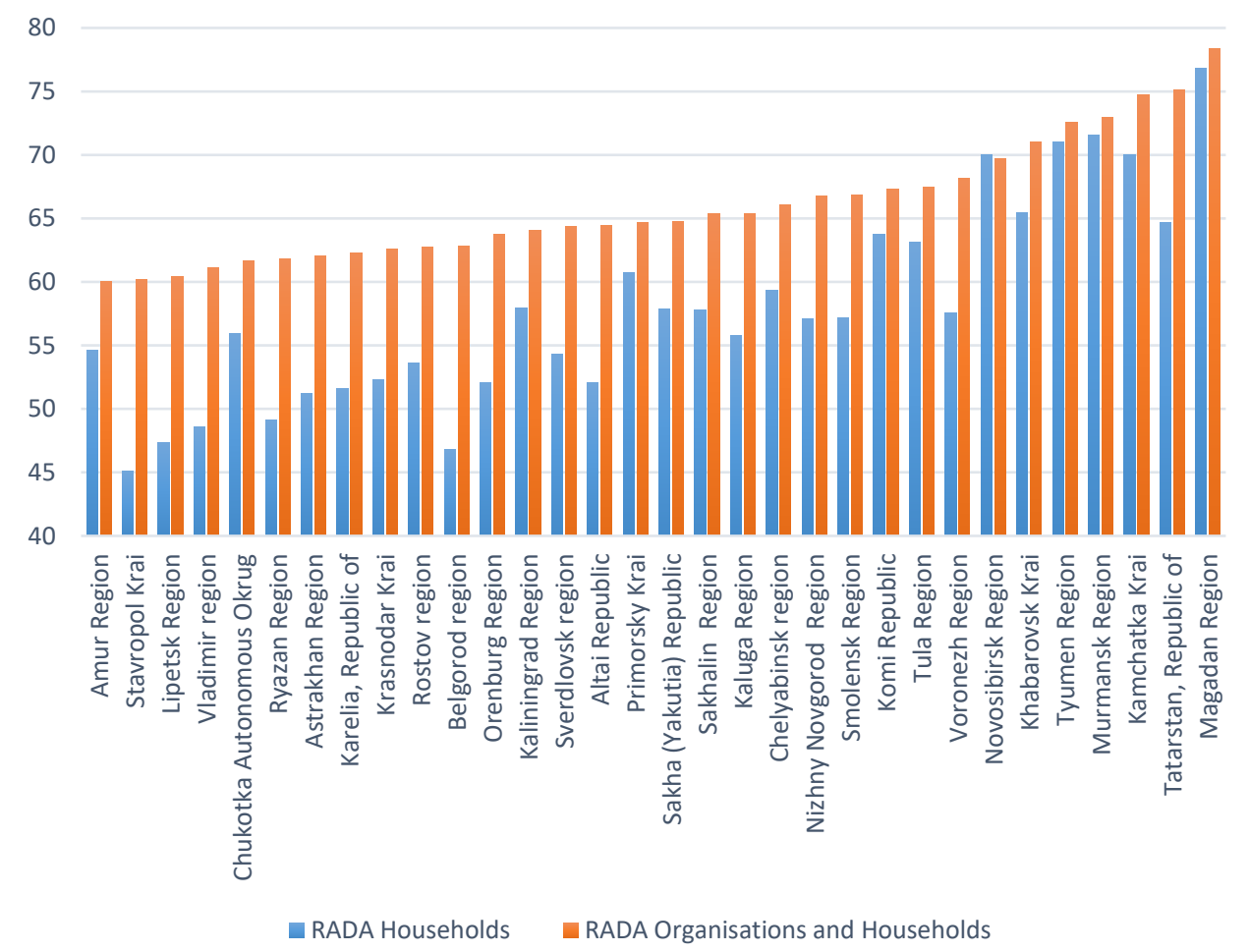

Fig. 1. High availability of digitalization

In Figure 1, one can see a relatively slight variation in the RADA values for households and the RADA for households with organizations. As the value of RADA decreases, this difference is becoming increasingly noticeable. The greatest lag (the difference of over 10 points) in this group is observed in 12 regions, including the Belgorod Region (16.03), Stavropol Territory (15.06), Lipetsk (13.06), Ryazan (12.68) and Vladimir (12.05) Regions. These regions have high values in the use of information and communication technologies in organizations and use of the Internet in organizations, and relatively low values for the 
number of subscribers with a fixed broadband connection per 100 people (from 16.3 to 24.7 subscribers per 100 people). For other analyzed indicators, these regions have a mid-level ranking, which led to the first group.

A group of regions with mid-level digital access, shown in Figure 2, includes 33 regions of 78. The best values of RADA for organizations and households in this group are observed in the Perm Territory, the Republic of Bashkortostan, and the Tambov Region. In 20 of the 33 of the above regions, there is a significant drop in RADA for households.

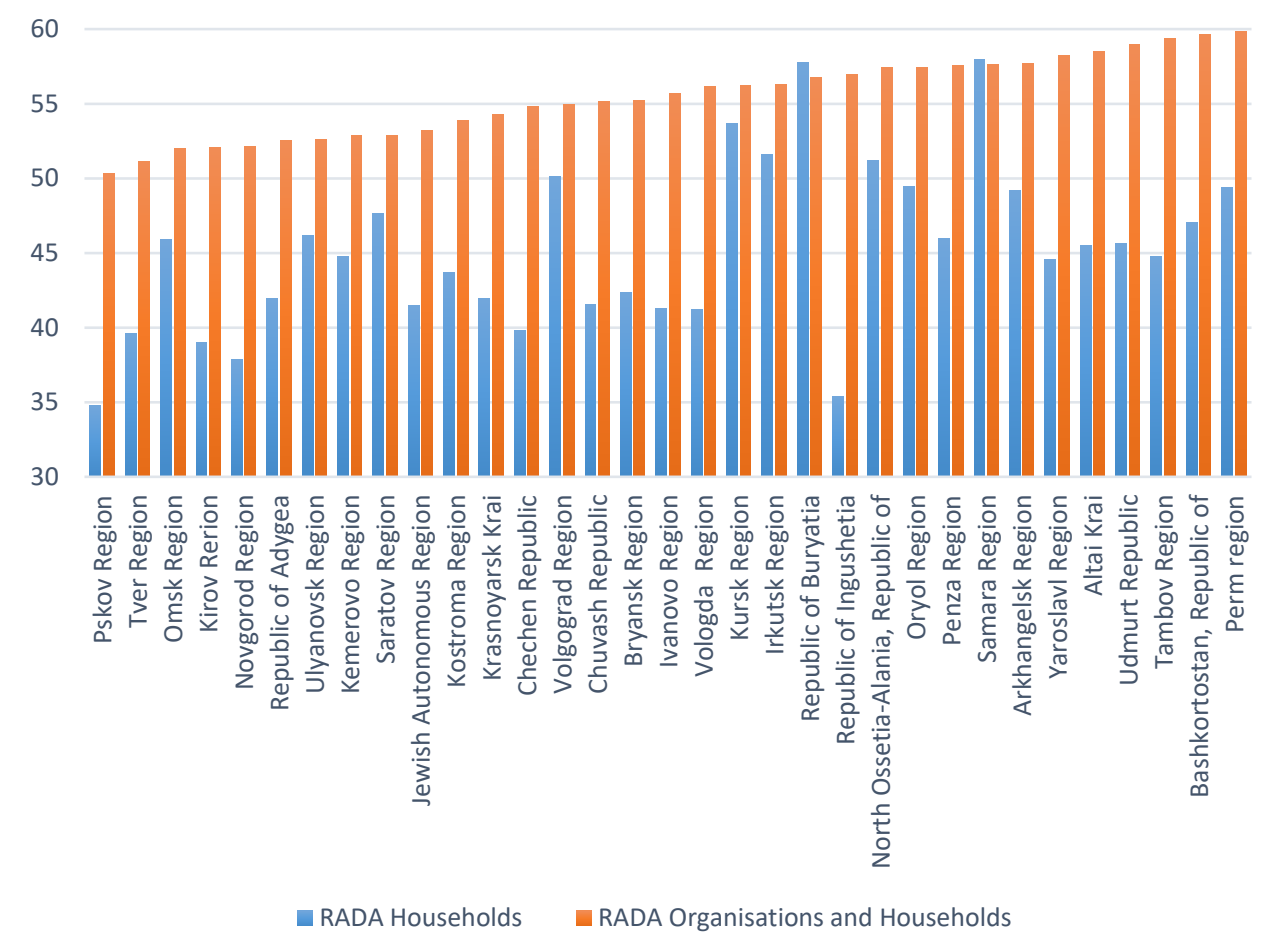

Fig. 2. Mid-level availability of digitalization

The largest lag (21.53) is observed in Ingushetia. According to Rosstat, the Republic endowed with the $100 \%$ use of informational and communications technologies in organizations has the share of households with access to the Internet of $85.2 \%$ which is a quite high level, comparing to other Russian regions. However, Ingushetia is significantly lagging behind in broadband access: the number of subscribers with a fixed broadband communication per 100 people is only 1.2 per 100 people, only 52.5 of 100 people are connecting via the broadband mobile Internet. Thus, the amount of data transmission is also very low (0.097 PB per 1000 person). Significant lag is observed in the Pskov Region (15.55), Chechen Republic (15.05), Vologda (14.93), Tambov (14.64), Ivanovo (14.4) and Novgorod (14.27) Regions. In the Samara Region and the Republic of Buryatia, RADA for households slightly exceeds RADA for organizations and households (by 0.36 and 0.99 , respectively). Unfortunately, it can be explained as a result of a low level of digitalization in organizations (only $76.3 \%$ of organizations use global information systems in Buryatia, $83.7 \%$ in the Samara Region. Also, the Samara Region ranks 76 of 78 in terms of using ICT technologies in organizations).

The third group of 13 regions shows the lowest digitalization level and demonstrates low values for both organizations and households. The gap of RADA for households with 
more than 10 points is observed in 7 of the 13 regions. The greatest lag is in Sevastopol (19.12), the Transbaikal Territory (18.8), Republic of Crimea (17.3), and Republic of Mordovia (12.88). Special attention must be paid to Crimea and Sevastopol as these regions fail in almost all the analyzed indicators, which points out the need for significant efforts in digital infrastructure development for these regions. Also, the Republic of Dagestan brings certain concerns, as there is a significant failure for the equipment with digital technologies of not only households but also organizations, as it displays the lowest level of digitalization.

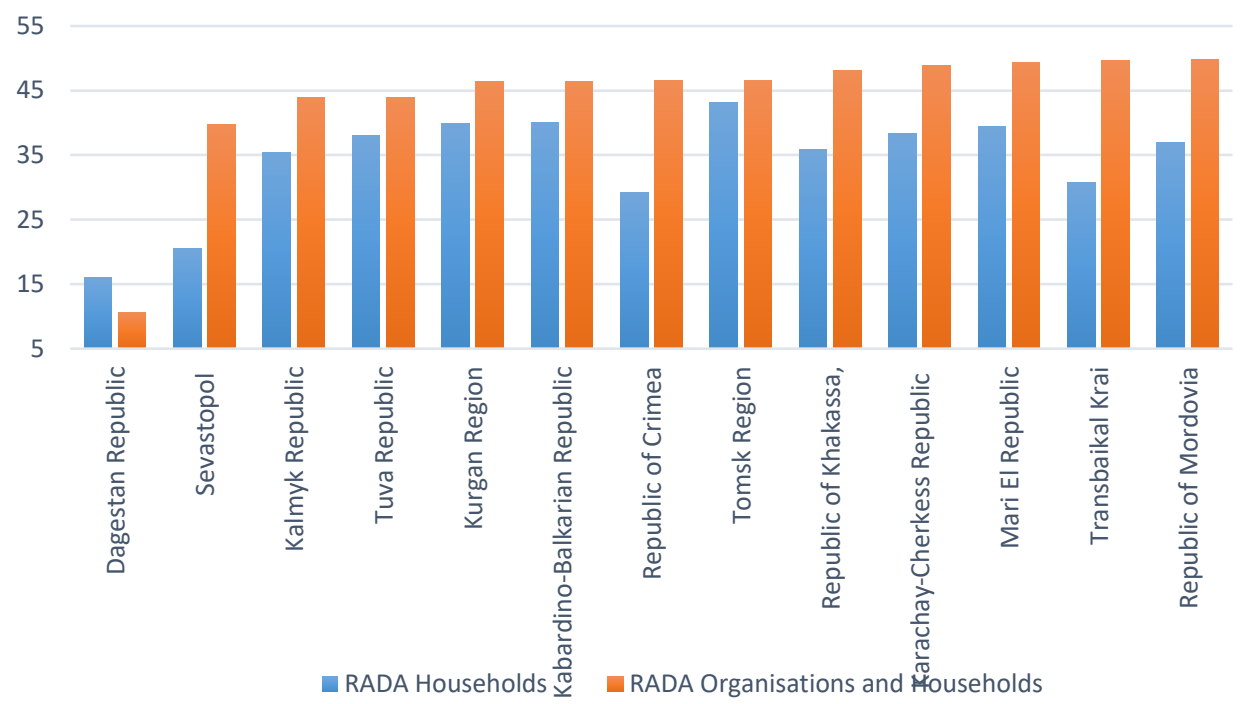

Fig. 3. Low level availability of digitalization

When analyzing inequalities in the regions, it is necessary not only to conduct a rating assessment but also to pay attention to the ratio between indicators inside the index. So in several regions with a relatively high proportion of households with a formal connection to the Internet (Republics of Tuva, Chechnya, Ingushetia), the share of broadband accounts, of not only fixed but also the mobile Internet, is low. This allows concluding a fairly low percentage of the stable Internet, which makes the processes of providing high-quality digital services to the population quite difficult. Some regions, for example, the Krasnodar Territory, Kamchatka Territory, and Sakhalin Region, demonstrate a high level of mobile Internet subscribers (over 100 accounts per 100 people) with a relatively low level of households connected to the Internet. This condition may be used as an indicator of the intraregional inequality when not all economic agents have access to the Internet, but the wealthy ones can afford several sources of mobile broadband access. Such a situation will also negatively affect digitalization processes, strengthening inequality in access to benefits and services provided by digital technologies.

\section{Discussion}

The results of the RADA index analysis show digital inequality in the readiness to employ the digitalization of the national economy between the Russian regions. A significant part of the regions falls behind in the level of Internet penetration into society. At the same time, if the level of digitalization of organizations is relatively high in most regions, the access to the Internet among households varies between the regions to a much greater extent. During 
this study, the authors have encountered some restrictions. These include the problem of mixed official statistics for some indicators of Moscow and St. Petersburg, which are separate subjects of the Federation, with the data of the Moscow and Leningrad Regions. Also, the RADA index does not allow estimating the level of inequality within the region, the difference in accessing digital technologies between urban and rural areas.

It should also be noted that the analysis was carried out with the data prior to the COVID-19 pandemic. The lockdowns and temporary remote work time for the part of employees could significantly affect the level of digitalization. The analysis of the influence of the pandemic on the development of digitalization seems an important direction for further research.

\section{Conclusion}

The rating built by the authors of this study allows estimating inequality in digitalization between Russian regions and identifying the origins of disproportions. This research shows that not all regions of Russia are equally ready for the digital economy. If organizations, in general, show a relatively high digitalization level, for the households, the situation is much less equal. This inequality can be associated with the insufficient use of the Internet by households, the lack of prevalence of broadband mobile access and fixed access to the Internet. Special attention should be paid to the strongly lagging regions, which include the regions of the Northern Caucasus, as well as the Crimea. It is necessary to identify the reasons for this lagging and take measures to equalize the level of digitalization of regions, which will expand their economic potential and the inclusion in the country's economic and social system.

\section{References}

1. J. A. G. M. Van Dijk, Poetics, 34, 221-235 (2006)

2. I. Mingo, R. Bracciale, Soc. Ind. Res., 135, 629-659 (2018)

3. E. Hargittai, New Economy handbook, 2003, 821-839 (2003)

4. D. L. Hoffman, T. P.Novak, The growing digital divide: Implications for an open research agenda, In Understanding the digital economy: Data, tools and research, 245260 (2000)

5. S. Nanthikesan, Trends in digital divide, (2000)

6. P. DiMaggio, E. Hargittai, From the 'digital divide' to 'digital inequality': Studying Internet use as penetration increases (2001)

7. A. Gladkova, M. Ragnedda, Online Inf. Rev., 44, 767-786. (2020)

8. N. Grishchenko, Telecom. Pol., 44, 102004. (2020)

9. G. P.Litvintseva, I. N. Karelin, Terra Economicus. 3, 53-71 (2020)

10. M. A. Polojikhina, Econ. and Soc. Probl. Of Russia, 2, 119-142 (2017)

11. O. V. Shinyaeva, O. M. Slepova, Izvestiya of Saratov University. Sociology. Politology, 1, 53-61 (2019)

12. E. A. Lyaskovskaia. Bulletin of South Ural State University, Series "Economics and Management", 15, 45-56 (2021)

13. T. F. Scharifyanov, Voprosy regionalnoj ekonomiki, 4, 125-142 (2020)

14. I. V. Groshev, A. A. Krasnoslobodtsev, Sociological Studies, 5, 66-78 (2020)

15. P. Sicherl, The Information Society, 35, 143-157 (2019) 